Article

\title{
Repurposing of Fluvastatin as an Anticancer Agent against Breast Cancer Stem Cells via Encapsulation in a Hyaluronan-Conjugated Liposome
}

\author{
Ji Su Yu ${ }^{1}$, Dae Hwan Shin ${ }^{2}$ and Jin-Seok Kim ${ }^{1, *}$ \\ 1 Research Institute of Pharmaceutical Science, College of Pharmacy, Sookmyung Women's University, \\ Cheongparo 47 gil 100, Yongsan gu, Seoul 04310, Korea; yujs0910@naver.com \\ 2 College of Pharmacy, Chungbuk National University, Cheongju 28160, Korea; dshin@chungbuk.ac.kr \\ * Correspondence: jsk9574@sookmyung.ac.kr; Tel.: +82-02-710-9574; Fax: +82-02-710-0032
}

Received: 5 November 2020; Accepted: 23 November 2020; Published: 24 November 2020

\begin{abstract}
Fluvastatin (FLUVA), which is a common anti-hypercholesterolemia drug, exhibits potential anticancer activity as it suppresses the proliferation, angiogenesis, and metastasis of breast cancer cells via inhibiting 3-hydroxy-methyl glutaryl-coenzyme A (HMG-CoA) reductase. In this study, hyaluronan-conjugated FLUVA-encapsulating liposomes (HA-L-FLUVA) were evaluated for their anticancer efficacy in vitro and in vivo. The particle size, zeta potential, and encapsulation efficiency of HA-L-FLUVA were $158.36 \pm 1.78 \mathrm{~nm},-24.85 \pm 6.26 \mathrm{mV}$, and $35 \%$, respectively. Growth inhibition of breast cancer stem cells (BCSCs) by HA-L-FLUVA was more effective than that by free FLUVA. The half maximal inhibitory concentration $\left(\mathrm{IC}_{50}\right)$ values of FLUVA, L-FLVUA, and HA-L-FLUVA were $0.16,0.17$, and $0.09 \mu \mathrm{M}$, respectively. The in vivo anticancer effect of HA-L-FLUVA in combination with doxorubicin (DOX) was more effective than that of free FLUVA, free DOX, and HA-L-FLUVA. The longest survival of mice was achieved by treatment with FLUVA $(15 \mathrm{mg} / \mathrm{kg})$ and HA-L-FLUVA (15 mg/kg) + DOX (3 mg/kg), followed by HA-L-FLUVA (15 mg/kg), Dulbecco's phosphate buffered saline, and DOX ( $3 \mathrm{mg} / \mathrm{kg})$. No more than $10 \%$ body weight loss was observed in the mice injected with FLUVA, indicating that the drug was not toxic. Taken together, these results indicate that HA-L-FLUVA could serve as an effective anticancer drug by inhibiting the growth of both breast cancer cells and cancer stem cells.
\end{abstract}

Keywords: fluvastatin; breast cancer stem cells; hyaluronan; drug delivery system; liposome

\section{Introduction}

Breast cancer is one of the most frequently diagnosed cancers in women and the leading cause of cancer-related deaths worldwide [1,2]. Breast cancer is a malignant tumor with invasive and metastatic abilities. The main cellular burden in breast cancer consists of the so-called bulk tumor cells and cancer stem cells (CSCs), which constitute a small percentage of the tumor bulk. CSCs possess the characteristics of both stem cells and cancer cells as they have the self-renewal capability of normal stem cells, as well as the independent growth, tumorigenicity, and metastatic potential of cancer cells [3]. In addition, they are resistant to conventional therapies, such as chemotherapy and radiotherapy $[4,5]$. The presence of a small population of breast CSCs (BCSCs) is recognized as one of the causes of breast cancer recurrence [6,7]. CSCs are characterized by a specific surface marker phenotype, and BCSCs have been identified to have the $\mathrm{CD} 44^{+} / \mathrm{CD} 24^{- \text {low }}$ phenotype [8,9]. Preclinical and clinical trials have attempted to establish novel therapeutic regimens that aim to eradicate CSCs for the complete treatment of cancer [10-12]. As CD44 is known to be overexpressed on BCSCs, surface marker-targeting ligand-conjugated drug delivery systems, such as liposomes, could be used to target BCSCs and enhance the overall therapeutic efficacy of drugs against breast cancer [13-15]. 
Fluvastatin (FLUVA), which is also known as a 3-hydroxy-methyl glutaryl-coenzyme A (HMG-CoA) reductase inhibitor, belongs to the class of lipid-lowering drugs that block the conversion of HMG-CoA to mevalonic acid [16-19]. Recent studies have reported that FLUVA is a novel therapeutic agent for breast cancer prevention and treatment [17]. FLUVA belongs to the class of drugs that inhibit the mevalonate pathway, which is essential for the synthesis of compounds that significantly affect several critical cellular functions, such as cell membrane integrity, cell signaling, and cell cycle progression. These functions are related to cancer initiation, growth, and metastasis [20-22]. Therefore, FLUVA inhibits the proliferation and angiogenic and metastatic properties of breast cancer cells and BCSCs [23]. However, FLUVA has a low oral bioavailability ( 24\%), short half-life, and $98 \%$ plasma protein binding. Therefore, a higher amount of FLUVA is required for cancer treatment than for treating hypercholesterolemia, which may give rise to the typical adverse effects of FLUVA, including hepatotoxicity, peripheral neuropathy, and rhabdomyolysis [24].

Hyaluronan (HA), which is also known as hyaluronic acid or hyaluronate, is a major extracellular matrix component $[25,26]$. It is synthesized as a large, negatively charged, unbranched polymer composed of repeating disaccharides of glucuronic acid and $\mathrm{N}$-acetylglucosamin [27]. It is a biodegradable and non-immunogenic biomaterial [28]. HA binds to CD44 on the cell surface, allowing the targeting of BCSCs that overexpress CD44 [29-31]. HA has also been reported to form a hydrophilic barrier and prolong the circulation time of HA-conjugated nanocarriers in blood [32].

Liposomes are the most common nanocarriers used for targeted drug delivery systems [33-35]. They have several advantages in overcoming obstacles to cellular uptake and improving the payload biodistribution [36]. Most solid tumors have unique pathological properties, such as extensive angiogenesis, defective vascular structures, and damaged lymphatic drainage systems [37]. Therefore, liposomes with a size ranging from 100 to $200 \mathrm{~nm}$ in diameter can easily penetrate the tumor and be retained for a prolonged period owing to the enhanced permeability and retention (EPR) effect [38]. In addition, the use of hydrophilic polymers, such as HA, to conjugate drugs to the liposome surface can prevent the uptake of drug-carrying liposomes by the reticuloendothelial system (RES) [39]. Moreover, targeting ligand-conjugated liposomes are delivered to the target site more effectively than the conventional non-conjugated liposomes [40].

In this study, HA-conjugated FLUVA-encapsulating (HA-L-FLUVA) liposomes were prepared and tested for their in vitro and in vivo anticancer effects using MCF-7-derived BCSCs and xenograft mouse models, respectively (Scheme 1).

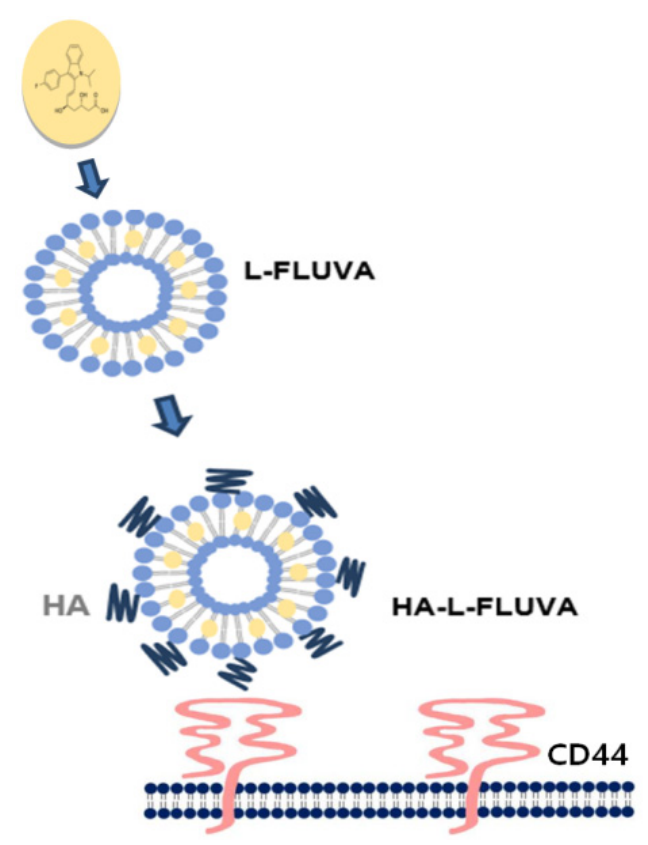

Scheme 1. Scheme of a hyaluronan (HA)-liposome and its interaction with CD44-positive cells. 


\section{Materials and Methods}

\subsection{Materials and Reagent}

FLUVA, HA (1500 kDa), 1-ethyl-3-(3-dimethyl-aminopropyl-carbodiimide) (EDC), poly-2-hydroxyethyl methacrylate (poly-HEMA), cholesterol, bovine serum albumin (BSA), basic fibroblast growth factor (bFGF), human epidermal growth factor (hEGF), insulin solution, dimethyl sulfoxide (DMSO), accutase, boric acid, paraformaldehyde, ethanol, methanol, and chloroform were purchased from Sigma-Aldrich (St. Louis, MO, USA). L- $\alpha$-phosphatidylcholine from egg (EPC) and 1,2-dioleoyl-snglycero-3-phosphonethanolamine (DOPE) were purchased from Avanti Polar Lipids (Alabaster, AL, USA). The MCF-7 human breast cancer cell line was purchased from the Korean Cell Line Bank (Seoul, Korea). RPMI-1640 (with L-glutamine and 25 mM HEPES), penicillin/streptomycin, Dulbecco's phosphate buffered saline (DPBS), and Trypsin-EDTA were purchased from Welgene, Inc. (Daegu, Korea). Fetal bovine serum (FBS), DMEM/F12, and B-27 supplement were purchased from Gibco (Grand Island, NY, USA). Anti-CD44-phycoerythrin (PE) and anti-CD24-fluorescein isothiocyanate (FITC) antibodies were purchased from Miltenyi Biotec (Bergisch Gladbach, Germany) and 17 beta-estradiol pellets (0.18 mg/60 days) were purchased from Innovative Research of America (Sarasota, FL, USA).

\subsection{Methods}

\subsubsection{Preparation of Liposomal FLUVA (L-FLUVA) and HA-L-FLUVA}

L-FLUVA was prepared by a thin lipid film hydration technique followed by freeze-thawing. L-FLUVA was composed of EPC, cholesterol, and DOPE (55:45:20 molar ratio). First, $52.8 \mu$ mol of lipid mixture in chloroform and FLUVA in methanol were mixed in a round-bottomed flask. The organic solvent in the mixture was evaporated using a rotary evaporator (Laborota 4000; Heidolph Instrument, Schwabach, Germany) under $6 \mathrm{~min}$ of exposure to nitrogen gas flow and then further evaporated for $45 \mathrm{~min}$ in a $42{ }^{\circ} \mathrm{C}$ water bath to form a thin lipid film. The lipid film was then hydrated using $10 \mathrm{mM}$ HEPES buffer ( $\mathrm{pH}$ 7.5). After hydration, the liposomes were subjected to 25 cycles of freezing (liquid nitrogen) and thawing $\left(42^{\circ} \mathrm{C}\right.$ water bath) to produce smaller unilamellar liposomes with an enhanced encapsulation efficiency. L-FLUVA was extruded using a mini-extruder (Avanti ${ }^{\circledR}$ polar lipid, Inc., Alabaster, AL, USA) through 800-, 400-, and 200-nm polycarbonate membrane filters (Whatman International, Ltd., Maidstone, UK), three times for each filter.

EDC coupling for amide synthesis was conducted to conjugate the HA onto the DOPE, which is lipid on the surface of L-FLUVA [41,42]. Briefly, $4 \mathrm{mg}$ of HA was dissolved in $1 \mathrm{~mL}$ of distilled water and mixed with $2 \mathrm{mg}$ of EDC. The mixture was activated at $\mathrm{pH} 4$ for $2 \mathrm{~h}$ at $37^{\circ} \mathrm{C}$. After activation, the HA solution was mixed with L-FLUVA (1:1 molar ratio of HA:liposome). The pH of the mixture was adjusted to 8.6 with $0.1 \mathrm{M}$ borate buffer ( $\mathrm{pH} 9.4$ ). The reaction was performed for $24 \mathrm{~h}$ at $37^{\circ} \mathrm{C}$. Unencapsulated FLUVA and unconjugated components were removed from the liposome solution by Sepharose gel column chromatography and ultracentrifugation $\left(20,000 \times g, 4{ }^{\circ} \mathrm{C}, 40 \mathrm{~min}\right)$.

\subsubsection{Analysis of the Size Distribution and Zeta Potential of the Liposome}

The size distribution and zeta $(\zeta)$-potential of liposomes were measured by dynamic laser-light scattering (SZ-100; Horiba, Japan). Each FLUVA liposomal formulation was diluted in distilled water at a 1:100 volume ratio and analyzed at $20-22^{\circ} \mathrm{C}$ with a scattering angle of $90^{\circ}$.

\subsubsection{Drug Encapsulation Efficiency}

FLUVA encapsulated in liposomes was extracted by the Bligh and Dyer extraction method [43]. Briefly, $100 \mu \mathrm{L}$ of liposome was mixed with $1 \mathrm{~mL}$ of chloroform, $250 \mu \mathrm{L}$ of methanol, and $150 \mu \mathrm{L}$ of DPBS. The mixture was vortexed until homogeneous. Next, it was centrifuged at $2700 \times g$ for $15 \mathrm{~min}$ at $20-22{ }^{\circ} \mathrm{C}$, resulting in separation into two phases. The lower (organic) phase contained lipophilic materials, including FLUVA in chloroform, and the upper (aqueous) phase contained hydrophilic 
materials in methanol. Next, $1 \mathrm{~mL}$ of chloroform was added to the lower organic phase, and the mixture was centrifuged again. These steps were repeated three times. The amount of FLUVA in the organic phase was measured at $304 \mathrm{~nm}$ using a UV spectrophotometer (Ultraspec 4000; Pharmacia biotech, Piscataway, NJ, USA). The FLUVA encapsulation efficiency (\%) of the liposomes was calculated using the following formula:

$$
\text { FLUVA encapsulation efficiency }(\%)=\left(\frac{\text { Amount of FLUVA in liposome }}{\text { Initial amount of FLUVA }}\right) \times 100 \text {. }
$$

\subsubsection{Culture of 2D Bulk Cells (MCF-7 Adherent Cells) and BCSCs (MCF-7 Non-Adherent Cells)}

The 2D bulk cells were cultured as monolayers in RPMI-1640 medium containing 10\% FBS and 100 unit/mL penicillin/streptomycin at $37^{\circ} \mathrm{C}$ in a $5 \% \mathrm{CO}_{2}$ incubator (Sanyo Electric Co., Ltd., Moriguchi City, Osaka, Japan). When the cells reached approximately $80 \%$ confluence, they were washed with DPBS, trypsinized for $2 \mathrm{~min}$ at $37^{\circ} \mathrm{C}$, and centrifuged at $125 \times g$ for $3 \mathrm{~min}$. Next, the cells were washed with serum-free medium containing 100 unit/mL penicillin/streptomycin, centrifuged again, and cultured as mentioned earlier.

For the non-adherent BCSC culture, the cultured 2D bulk cells were dissociated using Trypsin-EDTA, and single cells were cultured on poly-HEMA-coated culture dishes containing fresh culture medium. The BCSCs were cultured in serum-free medium containing $100 \mathrm{unit} / \mathrm{mL}$ penicillin/streptomycin, 0.4\% BSA, $5 \mu \mathrm{g} / \mathrm{mL}$ insulin, $20 \mathrm{ng} / \mathrm{mL} \mathrm{bFGF,} 20 \mathrm{ng} / \mathrm{mL} \mathrm{hEGF}$, and B-27 supplement in DMEM/F-12. Under these conditions, the 2D bulk cells grew as non-adherent spheres, called mammospheres. Fresh culture medium was added on the fourth day. The BCSCs were collected on the seventh day and dissociated into single cells using accutase $\left(10 \mathrm{~min}\right.$ at $\left.37^{\circ} \mathrm{C}\right)$.

\subsubsection{Flow Cytometric Analysis of BCSCs}

The BCSCs and 2D bulk cells were dissociated into single cells and washed twice with DPBS. For flow cytometric analysis, the single cells of BCSCs and 2D bulk cells were stained in the dark with anti-CD44-FITC and anti-CD24-PE antibodies in $100 \mu \mathrm{L}$ DPBS for $30 \mathrm{~min}$ at $4{ }^{\circ} \mathrm{C}$. The stained cells were washed and resuspended in cold DPBS. CD $44^{+} / \mathrm{CD} 24^{-/ \text {low }}$ surface markers were determined using a FACSCalibur ${ }^{\mathrm{TM}}$ flow cytometer (BD Bioscience, San Jose, CA, USA).

\subsubsection{Inhibition of BCSC Proliferation}

The anti-proliferative effect of FLUVA formulations in BCSCs was evaluated using a sphere-forming assay. Single cells of BCSCs were seeded in poly-HEMA-coated 96-well plates at a density of 2000 cells/well in $100 \mu \mathrm{L}$ of serum-free medium. The cells in each well were treated with free FLUVA or HA-L-FLUVA in the medium. The plates were incubated at $37^{\circ} \mathrm{C}$ in a $5 \% \mathrm{CO}_{2}$ incubator. After 7 days, the number of spheres with a diameter of $\geq 100 \mu \mathrm{m}$ was counted under a microscope (ix71; Olympus, Tokyo, Japan). To compare the inhibition of the sphere-forming ability, the half maximal inhibitory concentration $\left(\mathrm{IC}_{50}\right)$ was calculated using the following GraphPad Prism 9.0 (Prism Software, Inc., San Diego, CA, USA) formula:

$$
\mathrm{IC}_{50}=\frac{\text { sphere number of sample }}{\text { sphere number of control }} \times 100
$$

\subsubsection{Antitumor Effects of HA-L-FLUVA in Xenograft Mouse Models}

All mouse experiments were approved by the Institutional Animal Care and Use Committee of Sookmyung Women's University (SMU-IACUC), Korea. BALB/C nude mice (female, 5 weeks old) were purchased from Nara-Biotec (Seoul, Korea). All experiments were performed in accordance with SMU-IACUC guidelines and procedures (approval number: SMWU-IACUC-1906-015, 24 October 2019). The antitumor effect of HA-L-FLUVA was evaluated in a BCSC-xenografted mouse model. 
The mice were housed in ventilated cages with free access to water and food. $17 \beta$-estradiol pellets ( $0.18 \mathrm{mg} / 60$ days) were implanted subcutaneously (s.c.) around the neck to establish xenograft mouse models $[44,45]$. After 3 days, the BCSCs were harvested from the culture dishes and washed three times with DPBS. Next, BCSCs $\left(1 \times 10^{6}\right)$ in $40 \mu \mathrm{L}$ DPBS and $60 \mu \mathrm{L}$ Matrigel were injected s.c. into the right flank of the mice. Within 10 days, all mice developed tumors with a size of approximately 60-70 $\mathrm{mm}^{3}$. The mice were randomly distributed into five groups ( $\mathrm{n}=7$ per group). The mice in each group were injected retro-orbitally with DPBS (control), FLUVA (15 mg/kg), doxorubicin (DOX) (3 mg/kg), HA-L-FLUVA (15 mg/kg), or HA-L-FLUVA with DOX (HA-L-FLUVA (15 mg/kg) + DOX $(3 \mathrm{mg} / \mathrm{kg})$ ). The mice were injected with the respective FLUVA formulation every day for 2 weeks and/or DOX every 4 days for 2 weeks. The tumor size was measured using a Vernier caliper at 2- or 3-day intervals and calculated using the standard formula:

$$
\text { Tumor size }=\frac{(\text { width })^{2} \times \text { length }}{2} .
$$

\subsubsection{In Vivo Toxicity Determination}

The mice in each group were injected retro-orbitally with DPBS (control), FLUVA (15 mg/kg), DOX (3 mg/kg), HA-L-FLUVA (15 mg/kg), or HA-L-FLUVA (15 mg/kg) + DOX (3 mg/kg). FLUVA formulations were injected every day for 2 weeks and DOX was injected every 4 days for 2 weeks. The body weight changes of all groups were measured at 2- or 3-day intervals. The toxicity of drugs was defined as $>10 \%$ body weight loss, abnormal behavior, signs of discomfort, or the death of animals [46]. Normalization of body weight change was calculated by dividing the body weight by the initial body weight.

\subsubsection{Statistical Analysis}

All results are presented as the mean \pm standard deviation (SD). Multiple comparisons were conducted using two-way analysis of variance (ANOVA) with Turkey's post-hoc test for BCSC anti-proliferation data. In vivo parameters were performed using one-way ANOVA with Turkey's post-hoc test. A p-value of less than 0.05 was considered statistically significant.

\section{Results}

\subsection{Analysis of the Size Distribution, Zeta Potential, and FLUVA Encapsulation Efficiency (\%) of Liposomes}

The mean diameters of liposomes were $115.7 \pm 2.00$ and $158.4 \pm 1.78 \mathrm{~nm}$ for L-FLUVA and HA-L-FLUVA, respectively (Table 1). A proper particle size ranging from 100 to $200 \mathrm{~nm}$ is known to improve the biodistribution via accumulation in tumor tissues (the EPR effect) [38]. The zeta potential was $-8.13 \pm 7.72$ and $-24.85 \pm 6.26 \mathrm{mV}$ for L-FLUVA and HA-L-FLUVA, respectively.

The encapsulation efficiency was analyzed using UV spectrophotometry by detecting the absorbance of FLUVA at $304 \mathrm{~nm}$. The FLUVA encapsulation efficiency of L-FLUVA and HA-L-FLUVA was approximately $33 \%$ and $35 \%$, respectively.

Table 1. Mean diameter, zeta potential, and encapsulation efficiency of formulations.

\begin{tabular}{ccc}
\hline Formulation & L-FLUVA & HA-L-FLUVA \\
\hline Mean diameter $(\mathrm{nm})$ & $115.7 \pm 2.00$ & $158.4 \pm 1.78$ \\
Zeta potential $(\mathrm{mV})$ & $-8.13 \pm 7.72$ & $-24.85 \pm 6.26$ \\
Encapsulation efficiency $(\%)$ & $33 \pm 2.8$ & $35 \pm 3.4$ \\
\hline
\end{tabular}

\subsection{Cell Culture of $2 D$ Bulk Cells and BCSCs}

$2 \mathrm{D}$ bulk cells adhered to the surface of the culture dish and grew. BCSCs grew as non-adherent mammospheres in poly-HEMA-coated culture dishes (Figure 1A). To characterize the phenotypes 
of $2 \mathrm{D}$ bulk cells and BCSCs, cells were stained with $5 \mu \mathrm{L}$ anti-CD44-FITC and $5 \mu \mathrm{L}$ anti-CD24-PE. The population of BCSCs was identified as CD $44^{+} / \mathrm{CD} 24^{-/ \mathrm{low}}$. The percentage of BCSCs in mammospheres was $26.93 \%$, whereas that of 2D bulk cells was $2.05 \%$ (Figure $1 \mathrm{~B}$ ).

A
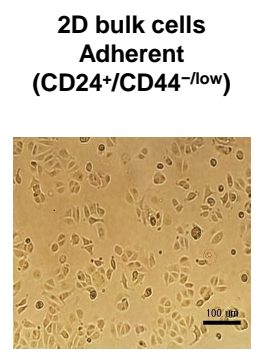

B

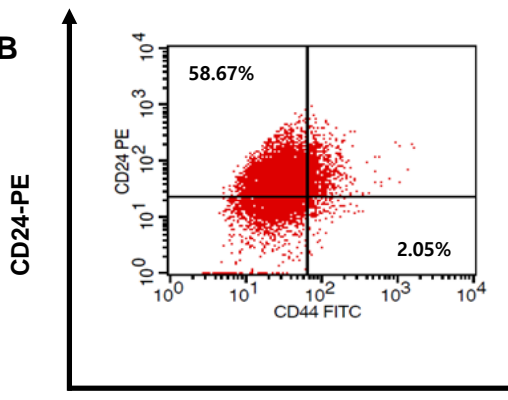

BCSCs

Mammospheres (CD24-/low/ CD44 ${ }^{+}$)
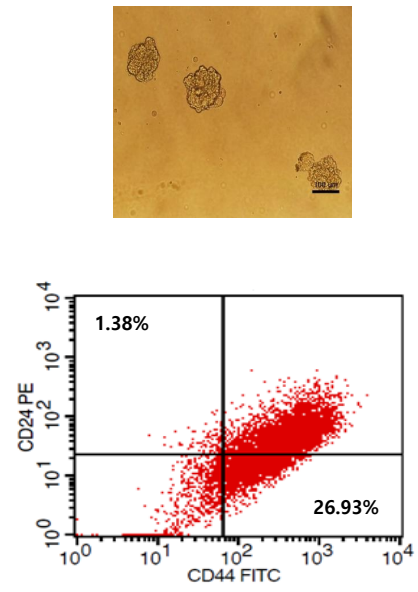

CD44-FITC

Figure 1. (A) Images of 2D bulk cells and breast cancer stem cells (BCSCs) under a light microscope (scale bar: $100 \mu \mathrm{m}$ ). (B) Phenotype characterization of 2D bulk cells and BCSCs via flow cytometry using anti-CD44-FITC and anti-CD24-PE staining.

\subsection{Inhibition of BCSC Proliferation}

To investigate the anti-proliferative effects of FLUVA in various formulations on BCSCs, we treated BCSCs with different FLUVA formulations for 7 days. The number and size of the spheres decreased when the FLUVA concentration was increased (Figure 2). The $\mathrm{IC}_{50}$ values of FLUVA, L-FLVUA, and HA-L-FLUVA were $0.16,0.17$, and $0.09 \mu \mathrm{M}$, respectively (Figure 3 and Table 2). The inhibitory effect of HA-L-FLUVA on sphere formation was approximately two-fold higher than FLUVA or L-FLUVA. There was no distinctive difference between FLUVA and L-FLVUA in this experiment.

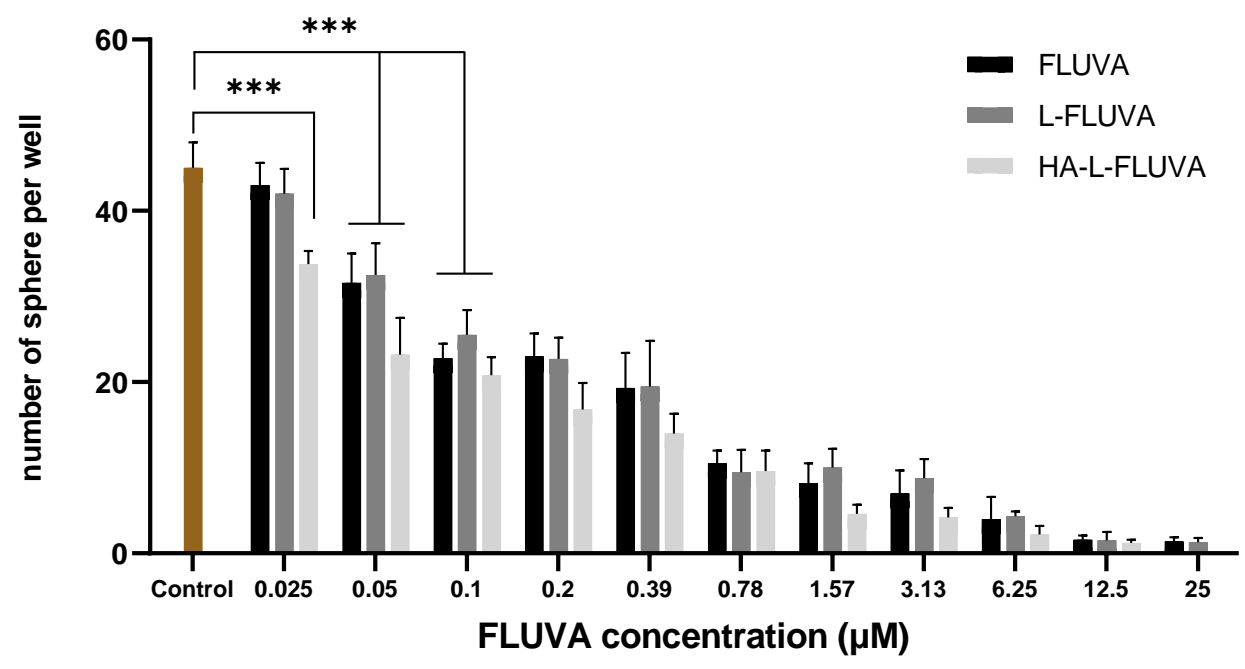

Figure 2. Number of spheres with a diameter of $\geq 100 \mu \mathrm{m}$ (mean $\pm \mathrm{SD}$, $\left.{ }^{* * *} p<0.001\right)$. 


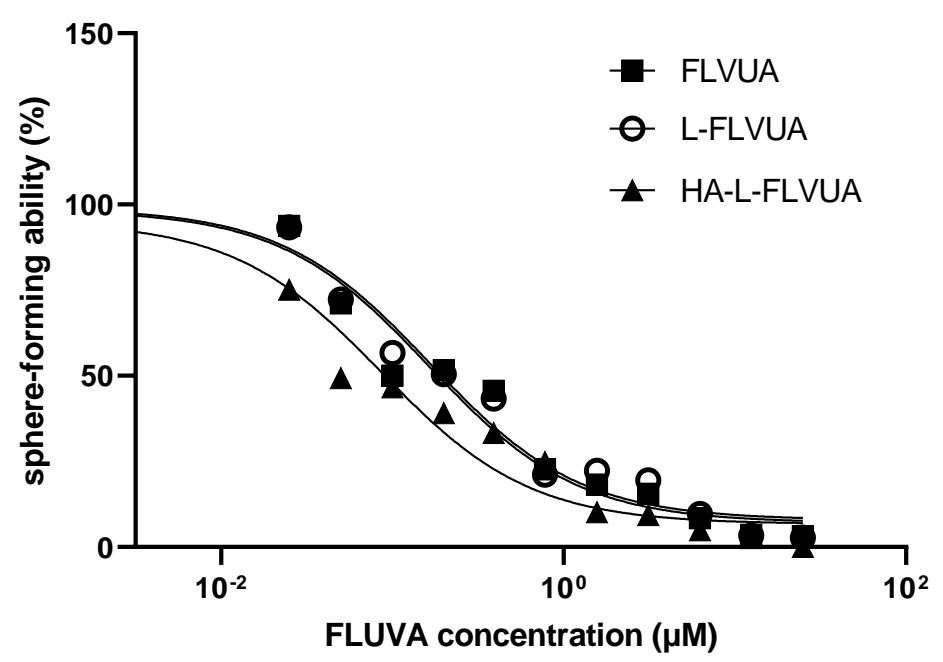

Figure 3. Anti-proliferative effect of fluvastatin (FLUVA) formulations on BCSCs, as assessed via a sphere-forming assay.

Table 2. The half maximal inhibitory concentration $\left(\mathrm{IC}_{50}\right)$ values of the sphere-forming ability (\%) of FLUVA, liposomal FLUVA (L-FLVUA), and hyaluronan-conjugated FLUVA-encapsulating liposomes (HA-L-FLUVA).

\begin{tabular}{cccc}
\hline Formulation & FLUVA & L-FLVUA & HA-L-FLUVA \\
\hline $\mathrm{IC}_{50}(\mu \mathrm{M})$ & 0.16 & 0.17 & 0.09 \\
\hline
\end{tabular}

\subsection{Antitumor Effects of HA-L-FLUVA in BCSC Xenograft Mouse Models}

The antitumor effect of HA-L-FLUVA was assessed in a BCSC-xenografted mouse model (BALB/C nude mice). HA-L-FLUVA displayed a more potent anticancer effect than free FLUVA and DOX (Figure 4). Furthermore, the DOX-treated group did not show effective anticancer effects. However, the mice co-treated with HA-L-FLUVA and DOX exhibited the smallest increase in tumor size among the five treatment groups and more prolonged remission than the mice subjected to the other drug treatments (Figure 4). Moreover, 100\% survival of mice was achieved by treatment with FLUVA $(15 \mathrm{mg} / \mathrm{kg})$ and HA-L-FLUVA $(15 \mathrm{mg} / \mathrm{kg})+$ DOX (3 mg/kg), whereas treatment with HA-L-FLUVA (15 mg/kg) and DPBS led to 85.7\% survival. Furthermore, DOX (3 mg/kg) led to the lowest survival rate of $71.4 \%$, as shown in Figure 5.

A

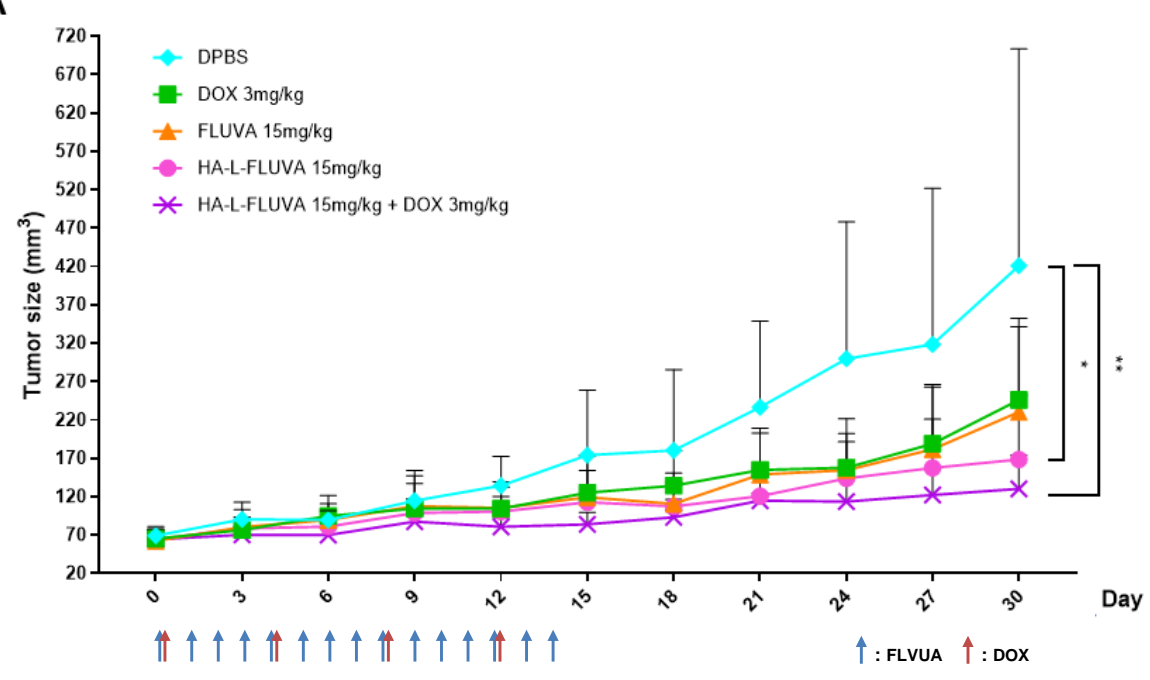

Figure 4. Cont. 
B

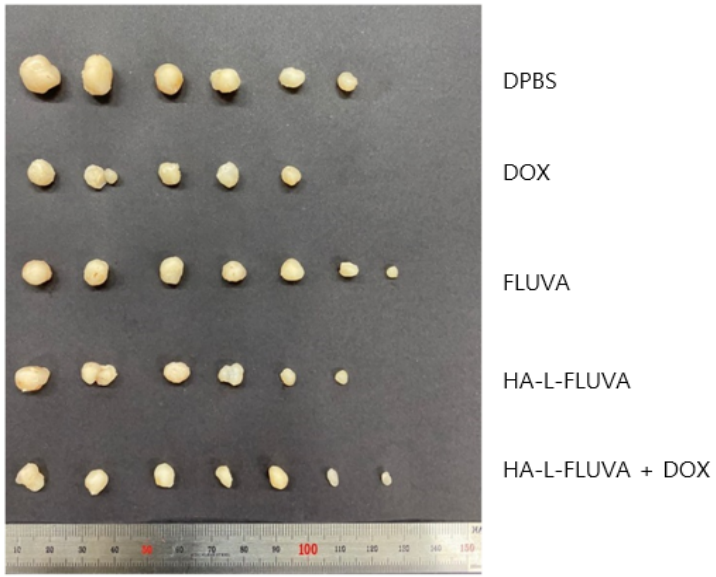

Figure 4. (A) Antitumor effect of HA-L-FLUVA in xenograft mouse models. Changes in tumor size in mice treated with Dulbecco's phosphate buffered saline (DPBS), doxorubicin (DOX), FLUVA, HA-L-FLUVA, and HA-L-FLUVA + DOX (mean $\pm \mathrm{SD},{ }^{*} p<0.05,{ }^{* *} p<0.01$ ). (B) Photographs of excised tumors from each group treated with DPBS, FLUVA, DOX, HA-L-FLUVA, and HA-L-FLUVA + DOX.

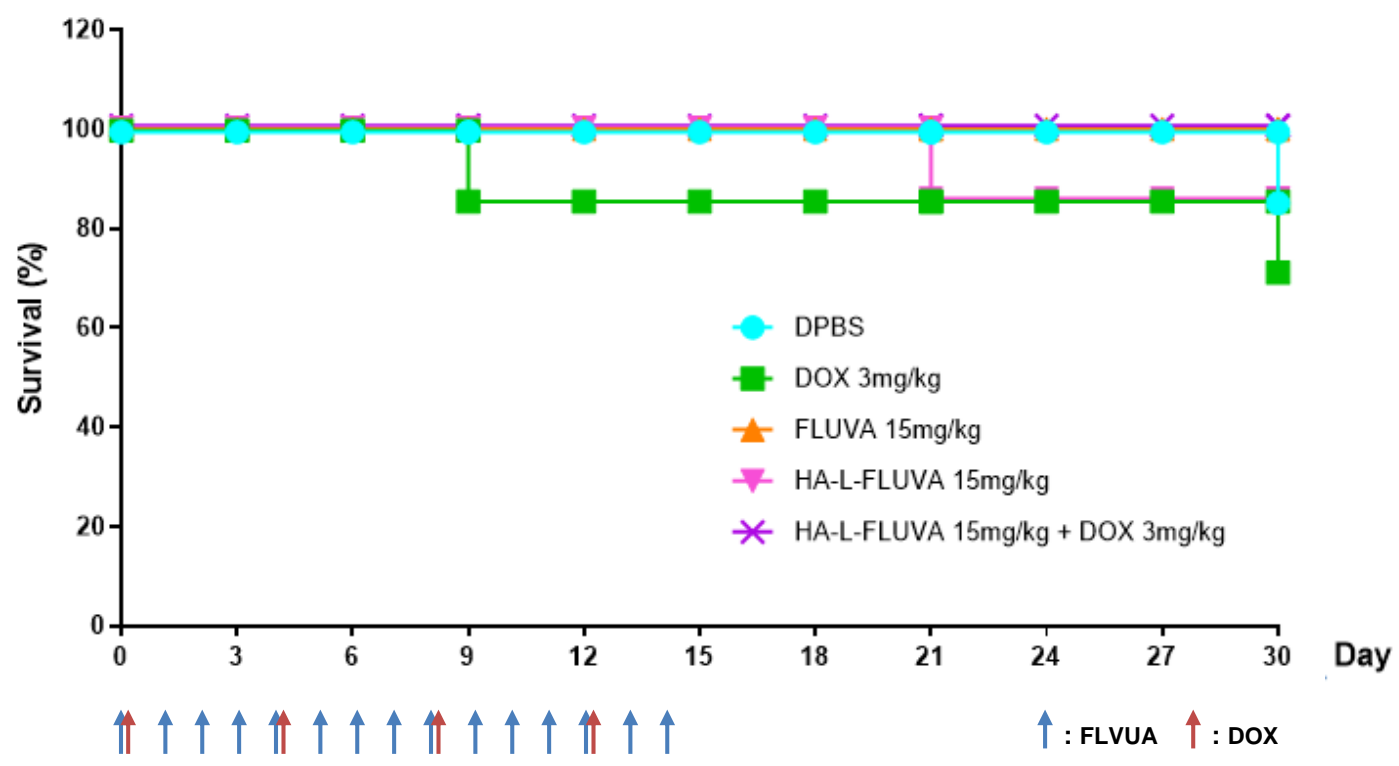

Figure 5. Kaplan-Meier plot showing the 30-day survival rate of a xenograft mouse model treated with DPBS, DOX, FLUVA, HA-L-FLUVA, and HA-L-FLUVA + DOX.

\subsection{Determination of the In Vivo Toxicity}

A decrease in mouse body weight after treatment with drugs is related to the toxicity of the drugs per se or the delivery system, such as liposomes. The toxicity of drugs was defined as a $>10 \%$ decrease in body weight. None of the drug-treated mice showed over a $10 \%$ body weight decrease during the 30-day period, which implies the absence of gross toxicity of the drug formulations used in the study (Figure 6). 


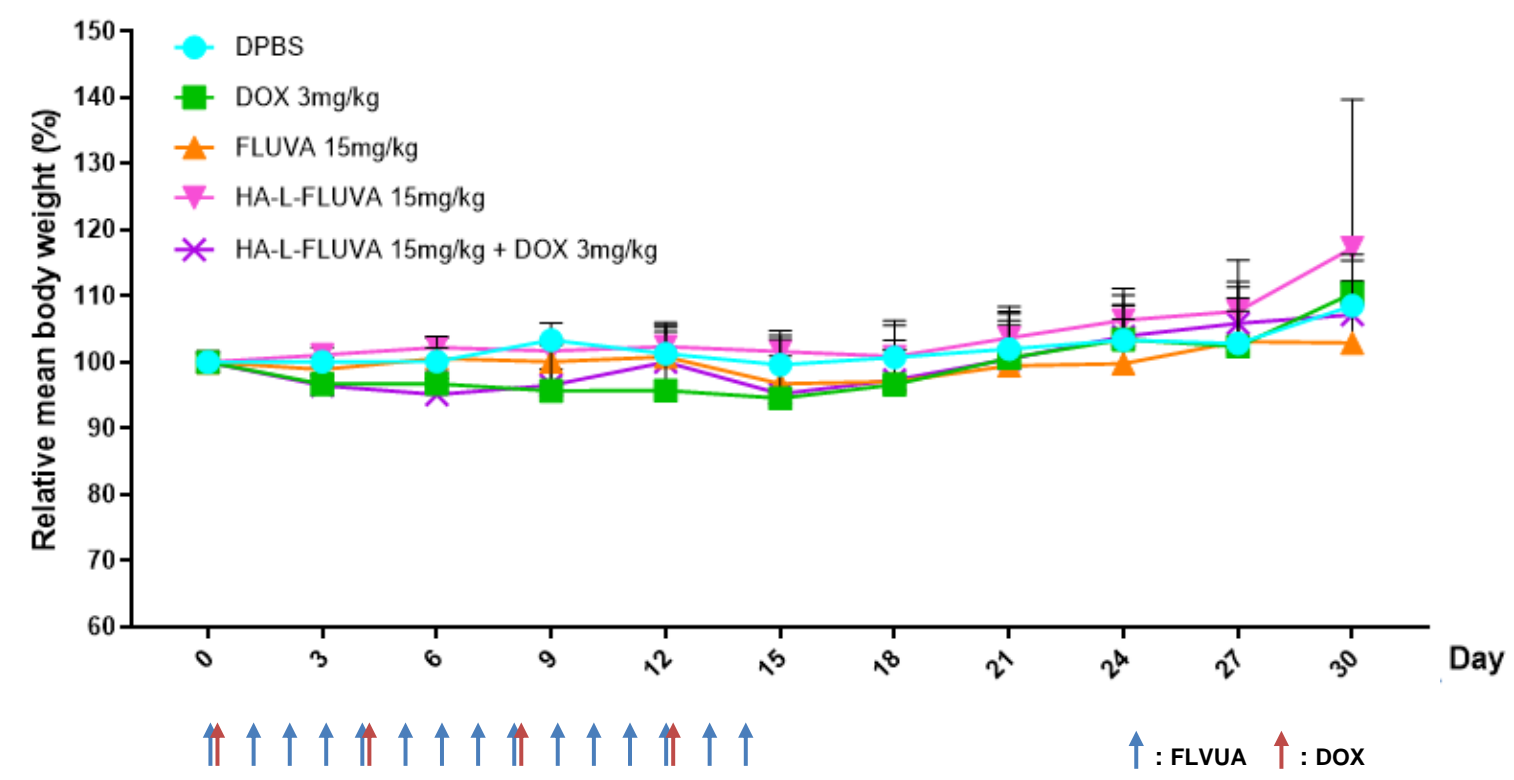

Figure 6. Normalized body weight changes in a xenograft mouse model after a retro-orbital injection of DPBS, DOX, FLUVA, HA-L-FLUVA, and HA-L-FLUVA + DOX.

\section{Discussion}

Recent studies state that most types of cancers may include CSCs, which are the main cause of recurrence and metastasis. One therapeutic strategy for breast cancer treatment is targeting the CD44 surface marker on BCSCs using HA.

Drug repurposing or drug repositioning is a strategy for identifying new uses of approved or investigational drugs that are outside the scope of the original medical indication [47]. FLUVA is a potent inhibitor of HMG-CoA reductase that can inhibit cholesterol synthesis or the isoprenoid pathway. Therefore, FLUVA can be used as an effective therapeutic agent for the prevention and treatment of breast cancer. However, the oral administration of FLUVA may cause some side effects, even though these side effects are less severe than the serious side effects of conventional anticancer agents. Therefore, we developed HA-L-FLUVA as an efficient anticancer agent that specifically targets BCSCs.

The particle size of HA-L-FLUVA was larger than that of L-FLUVA, which may be caused by the addition of HA on the surface of the liposome. The EPR effect is related to the particle size. Specific-sized liposomes of approximately 100-200 nm allow molecules to accumulate at tumor sites at higher concentrations than at normal sites and be retained for a long time [38]. The measured zeta potentials of L-FLUVA and HA-L-FLUVA were in the range of 0 to $-31 \mathrm{mV}$. Nanoparticles with a negative charge are much more stable and less toxic following an intravenous injection than particles with a positive or neutral charge. Therefore, we designed liposomes with suitable physicochemical characteristics for targeting BCSCs.

A subpopulation $\left(\mathrm{CD} 44^{+} / \mathrm{CD} 24^{-/ \text {low }}\right)$ of breast cancer cells has been reported to have stem cell properties $[8,9]$. To perform the targeting study, we identified the ratio of BCSCs and the 2D bulk cell population with the $\mathrm{CD} 44^{+} / \mathrm{CD} 24^{-/ \text {low }}$ phenotype. The percentage of BCSCs was 13 -fold higher than that of $2 \mathrm{D}$ bulk cells (Figure 1). This result is consistent with that of previous studies that cultured mammospheres that had a high percentage of $\mathrm{CD} 44^{+} / \mathrm{CD} 24^{-/ \text {low }}[48,49]$.

Suppression of the BCSC characteristics by FLUVA formulations was identified through a sphere-forming assay. The sphere formation assay was first designed more than 25 years ago to separate neural stem cells [50]. This method is widely used for assessing the stemness and enrichment of CSCs. This assay has been applied for the generation and maintenance of CSCs with a higher tumorigenicity [51]. In this study, the number and size of the spheres were decreased 
following treatment with an increased concentration of FLUVA formulations (Figure 2). These results indicated that FLUVA preferentially suppresses the self-renewal and proliferation properties of BCSCs. In addition, the anti-sphere formation effect of HA-L-FLUVA was much stronger than that of FLUVA and L-FLVUA (Figure 3 and Table 2). These results indicated that FLUVA exerted an anticancer effect and that HA-conjugated liposomes can enhance the effect of FLUVA by targeting BCSCs.

Finally, HA-L-FLUVA also showed a more distinctive in vivo anticancer effect than free FLUVA or DOX, as evidenced by the change in tumor size and survival rate in xenografted mice. The combination therapy with HA-L-FLUVA + DOX was the most effective among the five treatment groups, leading to more prolonged remission than that with the other drugs (Figure 4A). In addition, we investigated the anticancer effect and safety of various FLUVA formulations using Kaplan-Meier plots. All mice injected with FLUVA formulations were alive, although one death occurred in the group injected with HA-L-FLUVA. These results showed that there might be environmental factors other than the toxicity of the drug and liposome itself, and that it also has an anticancer effect. However, the death of mice in the group injected with DPBS and DOX is believed to be due to the increased cancer size and drug toxicity or other environmental factors (Figure 4B). Based on these results, FLUVA in the liposome formulation is likely to be protected from uptake by the RES, and the conjugation of HA to the surface of liposomes resulted in an increased stability and prolonged circulation in blood [32,41,52,53]. Based on the results shown in Figure 4A, HA-L-FLUVA probably showed the most potent anticancer effect and effective targeting of BCSCs. In addition, a loss of body weight of $>10 \%$ after drug injection in mice is usually related to the toxicity of the drug or delivery system [46]. All groups of mice showed a slight weight loss of less than $10 \%$ after drug injection, but this was not statistically confirmed (Figure 6). Therefore, the FLUVA formulations were shown to exert therapeutic efficacy without causing toxicity as a treatment of BCSCs in animals.

\section{Conclusions}

HA-L-FLUVA displayed much more potent anticancer effects than free FLUVA and DOX both in vitro and in vivo. HA served as a good targeting ligand for the CD44 surface marker of BCSCs, thereby allowing the specific delivery of FLUVA to BCSCs. Therefore, HA-L-FLUVA is expected to be useful as a novel therapeutic strategy for breast cancer therapy.

Author Contributions: Conceptualization, J.S.Y. and J.-S.K.; data curation, J.S.Y.; formal analysis, J.S.Y.; methodology, J.S.Y.; project administration, J.S.Y.; supervision, J.-S.K. and D.H.S.; writing-original draft, J.S.Y. and D.H.S.; writing-review and editing, J.S.Y. and D.H.S.; funding acquisition, J.-S.K. All authors have read and agreed to the published version of the manuscript.

Funding: This work was supported by the National Research Foundation of Korea (NRF) grant funded by the Korean government (MSIT) (No. 2020R1F1A1071972) and supported by the University Innovation Support Project through the National Research Foundation of Korea (NRF) funded by the Ministry of Education (MOE, Korea).

Acknowledgments: The authors would like to acknowledge Soo Bin Oh for her scientific and technical support.

Conflicts of Interest: The authors declare no conflict of interest.

\section{References}

1. Siegel, R.L.; Miller, K.D.; Jemal, A. Cancer statistics, 2018. CA Cancer J. Clin. 2018, 68, 7-30. [CrossRef] [PubMed]

2. Comsa, S.; Cimpean, A.M.; Raica, M. The Story of MCF-7 Breast Cancer Cell Line: 40 years of Experience in Research. Anticancer Res. 2015, 35, 3147-3154. [PubMed]

3. Lawson, J.C.; Blatch, G.L.; Edkins, A.L. Cancer stem cells in breast cancer and metastasis. Breast Cancer Res. Treat. 2009, 118, 241-254. [CrossRef] [PubMed]

4. Creighton, C.J.; Li, X.; Landis, M.; Dixon, J.M.; Neumeister, V.M.; Sjolund, A.; Rimm, D.L.; Wong, H.; Rodriguez, A.; Herschkowitz, J.I.; et al. Residual breast cancers after conventional therapy display mesenchymal as well as tumor-initiating features. Proc. Natl. Acad. Sci. USA 2009, 106, 13820-13825. [CrossRef] 
5. Dean, M.; Fojo, T.; Bates, S. Tumour stem cells and drug resistance. Nat. Rev. Cancer 2005, 5, $275-284$. [CrossRef]

6. Han, J.S.; Crowe, D.L. Tumor initiating cancer stem cells from human breast cancer cell lines. Int. J. Oncol. 2009, 34, 1449-1453.

7. Reya, T.; Morrison, S.J.; Clarke, M.F.; Weissman, I.L. Stem cells, cancer, and cancer stem cells. Nature 2001, 414, 105-111. [CrossRef]

8. Al-Hajj, M.; Wicha, M.S.; Benito-Hernandez, A.; Morrison, S.J.; Clarke, M.F. Prospective identification of tumorigenic breast cancer cells. Proc. Natl. Acad. Sci. USA 2003, 100, 3983-3988. [CrossRef]

9. Bozorgi, A.; Khazaei, M.; Khazaei, M.R. New Findings on Breast Cancer Stem Cells: A Review. J. Breast Cancer 2015, 18, 303-312. [CrossRef]

10. Aktas, B.; Tewes, M.; Fehm, T.; Hauch, S.; Kimmig, R.; Kasimir-Bauer, S. Stem cell and epithelial-mesenchymal transition markers are frequently overexpressed in circulating tumor cells of metastatic breast cancer patients. Breast Cancer Res. 2009, 11, R46. [CrossRef]

11. Holmes, F.A.; Espina, V.; Liotta, L.A.; Nagarwala, Y.M.; Danso, M.; McIntyre, K.J.; Osborne, C.R.; Anderson, T.; Krekow, L.; Blum, J.L.; et al. Pathologic complete response after preoperative anti-HER2 therapy correlates with alterations in PTEN, FOXO, phosphorylated Stat5, and autophagy protein signaling. BMC Res. Notes 2013, 6, 507. [CrossRef] [PubMed]

12. Ning, N.; Pan, Q.; Zheng, F.; Teitz-Tennenbaum, S.; Egenti, M.; Yet, J.; Li, M.; Ginestier, C.; Wicha, M.S.; Moyer, J.S.; et al. Cancer stem cell vaccination confers significant antitumor immunity. Cancer Res. 2012, 72, 1853-1864. [CrossRef] [PubMed]

13. Gangopadhyay, S.; Nandy, A.; Hor, P.; Mukhopadhyay, A. Breast cancer stem cells: A novel therapeutic target. Clin. Breast Cancer 2013, 13, 7-15. [CrossRef] [PubMed]

14. Scioli, M.G.; Storti, G.; D’Amico, F.; Gentile, P.; Fabbri, G.; Cervelli, V.; Orlandi, A. The Role of Breast Cancer Stem Cells as a Prognostic Marker and a Target to Improve the Efficacy of Breast Cancer Therapy. Cancers 2019, 11, 1021. [CrossRef] [PubMed]

15. Nascimento, T.L.; Hillaireau, H.; Vergnaud, J.; Fattal, E. Lipid-based nanosystems for CD44 targeting in cancer treatment: Recent significant advances, ongoing challenges and unmet needs. Nanomedicine 2016, 11, 1865-1887. [CrossRef] [PubMed]

16. Van Wyhe, R.D.; Rahal, O.M.; Woodward, W.A. Effect of statins on breast cancer recurrence and mortality: A review. Breast Cancer 2017, 9, 559-565. [CrossRef] [PubMed]

17. Campbell, M.J.; Esserman, L.J.; Zhou, Y.; Shoemaker, M.; Lobo, M.; Borman, E.; Baehner, F.; Kumar, A.S.; Adduci, K.; Marx, C.; et al. Breast cancer growth prevention by statins. Cancer Res. 2006, 66, 8707-8714. [CrossRef]

18. Ahern, T.P.; Lash, T.L.; Damkier, P.; Christiansen, P.M.; Cronin-Fenton, D.P. Statins and breast cancer prognosis: Evidence and opportunities. Lancet. Oncol. 2014, 15, e461-e468. [CrossRef]

19. Goldstein, J.L.; Brown, M.S. Regulation of the mevalonate pathway. Nature 1990, 343, 425-430. [CrossRef]

20. Ciofu, C. The statins as anticancer agents. Maedica 2012, 7, 377.

21. Hindler, K.; Cleeland, C.S.; Rivera, E.; Collard, C.D. The role of statins in cancer therapy. Oncologist 2006, 11, 306-315. [CrossRef] [PubMed]

22. Beckwitt, C.H.; Brufsky, A.; Oltvai, Z.N.; Wells, A. Statin drugs to reduce breast cancer recurrence and mortality. Breast Cancer Res. 2018, 20, 144. [CrossRef] [PubMed]

23. Kmietowicz, Z. Statins could be new treatment option in women with oestrogen receptor positive breast cancer. BMJ 2016, 353, i3108. [CrossRef] [PubMed]

24. Beltowski, J.; Wojcicka, G.; Jamroz-Wisniewska, A. Adverse effects of statins-mechanisms and consequences. Curr. Drug Saf. 2009, 4, 209-228. [CrossRef]

25. Misra, S.; Hascall, V.C.; Markwald, R.R.; Ghatak, S. Interactions between Hyaluronan and Its Receptors (CD44, RHAMM) Regulate the Activities of Inflammation and Cancer. Front. Immunol. 2015, 6, 201. [CrossRef]

26. Senbanjo, L.T.; Chellaiah, M.A. CD44: A Multifunctional Cell Surface Adhesion Receptor Is a Regulator of Progression and Metastasis of Cancer Cells. Front. Cell Dev. Biol. 2017, 5, 18. [CrossRef]

27. Toole, B.P. Hyaluronan: From extracellular glue to pericellular cue. Nat. Rev. Cancer 2004, 4, 528-539. [CrossRef]

28. He, L.; Gu, J.; Lim, L.Y.; Yuan, Z.X.; Mo, J. Nanomedicine-Mediated Therapies to Target Breast Cancer Stem Cells. Front. Pharmacol. 2016, 7, 313. [CrossRef] 
29. Bartolazzi, A.; Peach, R.; Aruffo, A.; Stamenkovic, I. Interaction between CD44 and hyaluronate is directly implicated in the regulation of tumor development. J. Exp. Med. 1994, 180, 53-66. [CrossRef]

30. Orian-Rousseau, V.; Ponta, H. Perspectives of CD44 targeting therapies. Arch. Toxicol. 2015, 89, 3-14. [CrossRef]

31. Arabi, L.; Badiee, A.; Mosaffa, F.; Jaafari, M.R. Targeting CD44 expressing cancer cells with anti-CD44 monoclonal antibody improves cellular uptake and antitumor efficacy of liposomal doxorubicin. J. Control. Release Off. J. Control. Release Soc. 2015, 220, 275-286. [CrossRef] [PubMed]

32. Song, S.; Qi, H.; Xu, J.; Guo, P.; Chen, F.; Li, F.; Yang, X.; Sheng, N.; Wu, Y.; Pan, W. Hyaluronan-based nanocarriers with CD44-overexpressed cancer cell targeting. Pharm. Res. 2014, 31, 2988-3005. [CrossRef] [PubMed]

33. Matsumura, Y.; Maeda, H. A new concept for macromolecular therapeutics in cancer chemotherapy: Mechanism of tumoritropic accumulation of proteins and the antitumor agent smancs. Cancer Res. 1986, 46, 6387-6392.

34. Torchilin, V.P. Recent advances with liposomes as pharmaceutical carriers. Nat. Rev. Drug Discov. 2005, 4, 145-160. [CrossRef] [PubMed]

35. Malam, Y.; Loizidou, M.; Seifalian, A.M. Liposomes and nanoparticles: Nanosized vehicles for drug delivery in cancer. Trends Pharmacol. Sci. 2009, 30, 592-599. [CrossRef]

36. Papahadjopoulos, D.; Allen, T.M.; Gabizon, A.; Mayhew, E.; Matthay, K.; Huang, S.K.; Lee, K.D.; Woodle, M.C.; Lasic, D.D.; Redemann, C.; et al. Sterically stabilized liposomes: Improvements in pharmacokinetics and antitumor therapeutic efficacy. Proc. Natl. Acad. Sci. USA 1991, 88, 11460-11464. [CrossRef] [PubMed]

37. Ogawara, K.; Yoshizawa, Y.; Un, K.; Araki, T.; Kimura, T.; Higaki, K. Nanoparticle-based passive drug targeting to tumors: Considerations and implications for optimization. Biol. Pharm. Bull. 2013, 36, 698-702. [CrossRef] [PubMed]

38. Maeda, H.; Wu, J.; Sawa, T.; Matsumura, Y.; Hori, K. Tumor vascular permeability and the EPR effect in macromolecular therapeutics: A review. J. Control. Release Off. J. Control. Release Soc. 2000, 65, 271-284. [CrossRef]

39. Moghimi, S.M.; Szebeni, J. Stealth liposomes and long circulating nanoparticles: Critical issues in pharmacokinetics, opsonization and protein-binding properties. Prog. Lipid Res. 2003, 42, 463-478. [CrossRef]

40. Trapani, G.; Denora, N.; Trapani, A.; Laquintana, V. Recent advances in ligand targeted therapy. J. Drug Target. 2012, 20, 1-22. [CrossRef]

41. Peer, D.; Margalit, R. Loading mitomycin C inside long circulating hyaluronan targeted nano-liposomes increases its antitumor activity in three mice tumor models. Int. J. Cancer 2004, 108, 780-789. [CrossRef] [PubMed]

42. Yerushalmi, N.; Margalit, R. Hyaluronic acid-modified bioadhesive liposomes as local drug depots: Effects of cellular and fluid dynamics on liposome retention at target sites. Arch. Biochem. Biophys. 1998, 349, 21-26. [CrossRef]

43. Bligh, E.G.; Dyer, W.J. A rapid method of total lipid extraction and purification. Can. J. Biochem. 1959, 37, 911-917. [CrossRef] [PubMed]

44. Kang, J.S.; Kang, M.R.; Han, S.B.; Yoon, W.K.; Kim, J.H.; Lee, T.C.; Lee, C.W.; Lee, K.H.; Lee, K.; Park, S.K.; et al. Low dose estrogen supplementation reduces mortality of mice in estrogen-dependent human tumor xenograft model. Biol. Pharm. Bull. 2009, 32, 150-152. [CrossRef] [PubMed]

45. Dall, G.; Vieusseux, J.; Unsworth, A.; Anderson, R.; Britt, K. Low Dose, Low Cost Estradiol Pellets Can Support MCF-7 Tumour Growth in Nude Mice without Bladder Symptoms. J. Cancer 2015, 6, 1331-1336. [CrossRef] [PubMed]

46. Kim, J.S.; Shin, D.H.; Kim, J.S. Dual-targeting immunoliposomes using angiopep-2 and CD133 antibody for glioblastoma stem cells. J. Control. Release Off. J. Control. Release Soc. 2018, 269, 245-257. [CrossRef]

47. Ashburn, T.T.; Thor, K.B. Drug repositioning: Identifying and developing new uses for existing drugs. Nat. Rev. Drug Discov. 2004, 3, 673-683. [CrossRef]

48. Jaggupilli, A.; Elkord, E. Significance of CD44 and CD24 as cancer stem cell markers: An enduring ambiguity. Clin. Dev. Immunol. 2012, 2012, 708036. [CrossRef] 
49. Sheridan, C.; Kishimoto, H.; Fuchs, R.K.; Mehrotra, S.; Bhat-Nakshatri, P.; Turner, C.H.; Goulet, R., Jr.; Badve, S.; Nakshatri, H. CD44+/CD24- breast cancer cells exhibit enhanced invasive properties: An early step necessary for metastasis. Breast Cancer Res. 2006, 8, R59. [CrossRef]

50. Reynolds, B.A.; Weiss, S. Generation of neurons and astrocytes from isolated cells of the adult mammalian central nervous system. Science 1992, 255, 1707-1710. [CrossRef]

51. Tirino, V.; Desiderio, V.; Paino, F.; Papaccio, G.; De Rosa, M. Methods for cancer stem cell detection and isolation. Methods Mol. Biol. 2012, 879, 513-529. [CrossRef] [PubMed]

52. Park, J.H.; Cho, H.J.; Yoon, H.Y.; Yoon, I.S.; Ko, S.H.; Shim, J.S.; Cho, J.H.; Park, J.H.; Kim, K.; Kwon, I.C.; et al. Hyaluronic acid derivative-coated nanohybrid liposomes for cancer imaging and drug delivery. J. Control. Release Off. J. Control. Release Soc. 2014, 174, 98-108. [CrossRef] [PubMed]

53. Peer, D.; Margalit, R. Tumor-targeted hyaluronan nanoliposomes increase the antitumor activity of liposomal Doxorubicin in syngeneic and human xenograft mouse tumor models. Neoplasia 2004, 6, 343-353. [CrossRef] [PubMed]

Publisher's Note: MDPI stays neutral with regard to jurisdictional claims in published maps and institutional affiliations.

(C) 2020 by the authors. Licensee MDPI, Basel, Switzerland. This article is an open access article distributed under the terms and conditions of the Creative Commons Attribution (CC BY) license (http://creativecommons.org/licenses/by/4.0/). 